\title{
IMMUNOLOGIC MEMORY CELLS OF BONE MARROW ORIGIN
}

\author{
InCreased Burst Size of Specific Immunocyte Precursors* \\ BY HAROLD C. MILLER: AND GUSTAVO CUDKOWICZ \\ (From the Department of Pathology, School of Medicine, State University of New York \\ at Buffalo, Buffalo, New York 14214)
}

(Received for publication 27 December 1971)

Bone marrow- and thymus-derived cells cooperate in humoral antibody responses of mice to xenogeneic erythrocytes (1-4) and to several other natural (5-8) or synthetic (9) macromolecules, including hapten-carrier conjugates (10-12). Both cell types are antigen reactive and antigen specific inasmuch as they become sensitized (11-16) or tolerant (5-7) independently of each other and are subject to quantitative and qualitative influences of determinant-specific immune response genes $(9,17)$. Separate banding of bone marrow precursors of immunocytes responsive to burro or sheep erythrocytes by density gradient centrifugation directly demonstrated antigen specificity in potentially immunocompetent cells that were still thymus and antigen dependent for the realization of their potential (18). An antigen suicide technique gave another demonstration of specificity for the more differentiated or mature cells of bone marrow origin residing in the spleen (8).

The object of this communication is to examine the properties of immunologic memory cells, which the hapten-carrier $(11,12)$ and our previous work $(14,15)$ suggest to be of bone marrow origin. For this purpose we determined whether or not immunologic memory could be adoptively transferred by specifically sensitized marrow cells in cooperation with nonsensitized thymocytes. This approach originates from the observation that the number of marrow cells specifically responsive to sheep red blood cells (SRBC) ${ }^{1}$ increases upon immunization of mice, but that such cells remain thymus dependent (14-16).

\section{Materials and Methods}

The studies were carried out using a syngeneic cell transfer system in $(\mathrm{C} 57 \mathrm{BL} / 10 \times \mathrm{C} 3 \mathrm{H} /$ $\mathrm{He}) \mathrm{F}_{1}$ female mice. The thymus of 6-8-wk-old nonimmune animals was the source of antigen-

* Supported in part by research grants AM-13,969 from the National Institute of Arthritis and Metabolic Diseases, National Institutes of Health, and IC-35B from the American Cancer Society.

$\ddagger$ Present address: Department of Microbiology and Public Health, Michigan State University, East Lansing, Mich. 48823.

${ }^{1}$ Abbreviations used in this paper: ARC, antigen-reactive cells of thymic origin; $\mathrm{PFC}$, plaque-forming cells; P-PFC, precursors of plaque-forming cells of bone marrow origin; P-PFC*, precursor cells specifically primed for producing larger numbers of PFC; SRBC, CRBC, HRBC, sheep, chicken, and horse erythrocytes, respectively; S. tm., Salmonella typhimurium. 
reactive helper cells (ARC), ${ }^{2}$ and the bone marrow of nonimmune or immune adult mice was the source of precursors of immunocytes. Details of the preparation of cell suspensions, the total body $\gamma$-irradiation of recipients, and the transplantation of cell mixtures have been given elsewhere $(4,14,15,18)$. Washed SRBC were used as the test antigen; and washed horse red blood cells (HRBC), chicken red blood cells (CRBC), and killed Salmonella typhimurium $(S . t m$.$) , as the control antigens.$

Groups of 12-16-wk-old mice were exposed to 950 rads of $\gamma$-irradiation and injected intravenously with a fixed number of $5 \times 10^{7}$ thymocytes, providing an excess of ARC, together with graded, limiting numbers of marrow cells providing small numbers of antibodyforming cell precursors. All irradiated mice received $5 \times 10^{8}$ xenogeneic erythrocytes intravenously 1 day later. In a few experiments, virgin thymocytes were replaced with educated thymus-derived cells, i.e., with cells of one-half of one mouse spleen harvested 5 days after irradiation and reconstitution of the mouse with $5 \times 10^{7}$ thymocytes and $5 \times 10^{8}$ $\mathrm{SRBC}$, as has been described (4). In some experiments, the immune response was assessed in terms of the number of cells secreting $\gamma \mathrm{M}$ or $\gamma \mathrm{G}$ hemolytic antibody (direct and indirect plaque-forming cells or $\mathrm{PFC}$, respectively) in the spleens of recipients at the time of peak response. In others, the immune response was assessed in terms of hemolytic foci of the spleen (clusters of plaque-forming cells presumably derived from a single antigen-sensitive unit), using the frozen spleen slice method on agar (19) and the micropiece mapping method in agarose $(20,21)$.

\section{RESULTS}

The concentration of precursors of plaque-forming cells (P-PFC) in the bone marrow of immune and nonimmune mice had previously been estimated by limiting dilution assays $(14,15)$. On day 9 after transplantation, recipient spleens were classified as negative or positive according to their content of newly formed PFC. The spleens were regarded as negative if the number of direct PFC was 200 or less, and that of indirect PFC, 100 or less. It was anticipated, and later verified, that the number of nucleated marrow cells containing an average of one detectable P-PFC would yield only $63 \%$ mice with positive spleens upon transplantation of this inoculum into a sufficiently large group of animals (Poisson statistics). It was assumed that each marrow P-PFC had an equal probability of reaching the recipient spleen, interacting with ARC and antigen, and generating PFC.

Of several groups of mice injected with graded numbers of marrow cells, we selected those groups with either near $63 \%$ or fewer positive spleens, and report the values of PFC per spleen in Table I. It can be safely stated that most of the positive spleens were seeded by one responding P-PFC and that the mean values of anti-sheep erythrocyte $\mathrm{PFC}$ per spleen therefore reflected the precursors' burst size (number of PFC generated by one precursor unit). The experiments were done with three groups of marrow donors: $(a)$ nonimmune mice; $(b)$ mice injected 3-4 months earlier with one of the control antigens other than SRBC; $(c)$ mice injected 2-3.5 months earlier with $5 \times 10^{8}$ SRBC.

\footnotetext{
2 The original designation of ARC is used for the thymus cells that proliferate upon exposure to antigens and thus generate the inducer or helper cells (4), even though it is realized that cells of nonthymic origin also react with antigers.
} 
The data clearly indicate that the P-PFC of specifically immunized mice generated more PFC than those of nonimmune mice or of animals injected with the control antigens. Neither the marrow nor the thymus cell suspensions produced an appreciable number of PFC on their own $(14,15)$. Moreover, the replacement of virgin thymocytes with educated thymus-derived cells $(\sim 5 \times$ $10^{6}$ spleen cells of irradiated mice reconstituted with $5 \times 10^{7}$ thymocytes and

TABLE I

Increased Burst Size of Bone Marrow Precursors of Plaque-Forming Cells after Immunization*

\begin{tabular}{|c|c|c|}
\hline $\begin{array}{l}\text { Immunization } \\
\text { of donor mice }\end{array}$ & $\begin{array}{c}\text { Marrow cells } \\
\text { transplanted }\left(\times 10^{5}\right)\end{array}$ & $\begin{array}{l}\text { Antibody-forming cells per } \\
\text { positive spleen } \$\end{array}$ \\
\hline \multicolumn{3}{|c|}{ Direct plaque-forming cells } \\
\hline None & $0.08-0.62$ & $370 \pm 31$ \\
\hline None\$ & 2.50 & $420 \pm 46(16)$ \\
\hline $\begin{array}{l}\text { HRBC, CRBC, } \\
\text { S.tm. (3-4 months) }\end{array}$ & $0.15-0.62$ & $551 \pm 91(32)$ \\
\hline SRBC (2 months) & $0.31-1.25$ & $495 \pm 80(10)$ \\
\hline SRBC (3.5 months) & $0.15-2.00$ & $1015 \pm 163(48)$ \\
\hline SRBC (3.5 months) $\$$ & 2.50 & $1041 \pm 153(11)$ \\
\hline \multicolumn{3}{|c|}{ Indirect plaque-forming cells } \\
\hline None & $0.08-10.00$ & $229 \pm 41(49)$ \\
\hline Noneई & 2.50 & $273 \pm 42(5)$ \\
\hline $\begin{array}{l}\mathrm{HRBC}, \mathrm{CRBC}, \\
\text { S.tm. 3-4 months) }\end{array}$ & $0.15-2.50$ & $300 \pm 49(27)$ \\
\hline SRBC (2 months) & $0.31-1.25$ & $784 \pm 270(11)$ \\
\hline SRBC (3.5 months) & $0.15-1.00$ & $877 \pm 184(32)$ \\
\hline SRBC (3.5 months) $\S$ & 2.50 & $1401 \pm 172(18)$ \\
\hline
\end{tabular}

* This table shows selected data from limiting dilution assays reported elsewhere (15). Groups of mice in which the incidence of positive spleens for PFC was $63 \%$ or less were chosen because, according to Poisson statistics, these spleens were seeded by one precursor unit, on the average, or by none.

$\ddagger$ Geometric means \pm standard errors are given with the number of spleens assayed in parentheses.

$\S$ Educated instead of virgin thymus cells were used.

$5 \times 10^{8} \mathrm{SRBC}$ ) (4) did not cause a further increase in the number of PFC per spleen. Considering that "background" $\mathrm{PFC}$ are included in the values of Table I, the ability of immune or educated P-PFC (hereafter P-PFC*) to generate immunocytes was increased by a factor of $3-5$ for $\gamma \mathrm{M}$ and $\gamma \mathrm{G}$ antibody.

The increased immunocompetence of P-PFC* was presumably due to a greater proliferative activity upon stimulation by appropriate antigens in the presence of virgin thymus-derived cells. Each P-PFC* could have generated descendent immunocytes in one discrete focal area of the spleen, as do virgin P-PFC (22-24), or in multiple focal areas. The difference between virgin and 
educated P-PFC would be less impressive in the former case than in the latter since only the size of a clone of antibody-forming cells would be changed, the mode of production remaining essentially the same. For the second possibility one would have to assume that appropriately stimulated P-PFC* first replicate and that their progeny cells migrate to other splenic sites before engaging in the terminal steps of proliferation and differentiation into PFC.

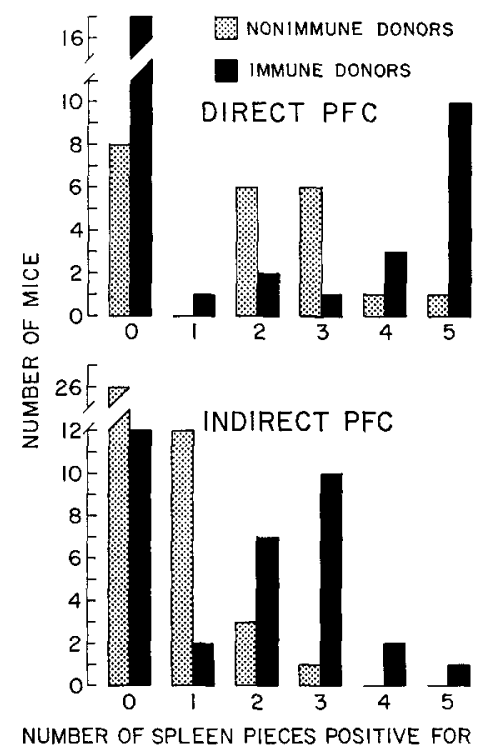

FIg. 1. Multicentric distribution of antibody-forming cells in spleens of irradiated mice injected with $5 \times 10^{7}$ thymocytes, $5 \times 10^{8} \mathrm{SRBC}$, and limiting numbers of bone marrow cells from immune $\left(1-2 \times 10^{5}\right.$ cells) or nonimmune donors $\left(0.31-1.25 \times 10^{5}\right.$ cells for direct PFC, and 0.62-5 $\times 10^{5}$ for indirect PFC). Recipient spleens were cut in five pieces, and each piece was assayed separately for PFC.

Two experiments were designed to test these possibilities. Groups of irradiated mice (950 rads of $\gamma$-rays from ${ }^{137} \mathrm{Cs}$ ) were grafted with an excess of thymocytes and limiting numbers of bone marrow cells from immune or nonimmune donors (as indicated in Fig. 1), and then injected with $5 \times 10^{8}$ SRBC. The marrow cells provided recipient spleens with less than one marrow P-PFC, on the average. Control mice were injected with marrow cells alone and SRBC to verify that the P-PFC* were thymus dependent. 9 days after transplantation, the spleens of recipient mice were cut transversally into five nearly equal pieces, as has been described earlier (23). The cells of each piece were dispersed and assayed separately for direct and indirect PFC, and each piece was classified as positive or negative. The incidence of spleens with increasing numbers of positive pieces is given in Fig. 1. Most recipient spleens seeded by 
virgin P-PFC were either entirely negative or had two to three positive pieces for direct PFC and one to two for indirect PFC. The absence of spleens with one positive piece for direct PFC was probably due to the relatively small sample size. Most importantly, the majority of the spleens seeded by P-PFC* were either negative or had a larger number of positive pieces, e.g., four to five for direct PFC and two to three for indirect PFC. A comparison of the two groups of recipients makes it clear that the PFC generated by a limited number of precursor cells (average of one or less) were distributed over a larger number of pieces when the marrow donors had been immunized to the test antigens.

The second experiment was identical to the first with regard to transplantation of bone marrow and thymus cells, but differed for the assay methods used. 8 or 9 days after transplantation, the numbers of hemolytic foci were determined by two different methods (19-21). Both procedures were more accurate than the macropiece method in determining the location and number of clusters of PFC descending from one precursor unit. However, direct and indirect PFC could be enumerated in dispersed cell suspensions of each macropiece, but only clusters of direct PFC could be detected in spleen slices laid over, or micropieces incorporated into, semisolid agar. Since the results obtained with the two assays were comparable, the data were pooled for presentation in Table II. Recipient spleens were again seeded by one, a few, or no P-PFC. Using the Poisson model, we calculated the theoretical probability of splenic colonization by different numbers of P-PFC among mice grafted with the number of marrow cells containing one detectable P-PFC, on the average (Table II). If one now assumes that each marrow precursor of $\mathrm{PFC}$ forms one hemolytic focus upon interaction with thymocytes and SRBC, the predicted frequency of colonization by one, more than one, or no P-PFC should coincide with the observed frequency distribution of foci. If, however, each marrow P-PFC* of immune donors forms a multiplicity of foci, then the observed frequency of spleens with more than one focus should exceed the predicted frequency of spleen colonization by more than one P-PFC*, whereas the observed and predicted frequencies of negative spleens should still coincide.

Several mice with negative spleens for anti-sheep erythrocyte hemolytic foci were found among recipients of virgin and educated P-PFC (Table II). The proportion of negative spleens was 24.5 and $34.0 \%$, respectively, as anticipated by the Poisson model for marrow inocula containing an average of one P-PFC. For inocula of nonimmune marrow, the frequency of spleens with one to four foci was generally compatible with the expectations, although there was a slight excess of spleens with one focus. It was of greater interest and consequence that there was no excess of spleens with a multiplicity of foci, in keeping with the one P-PFC, one focus, hypothesis (22-24). The results differed sharply for immune marrow: even though the inocula contained an average of one P-PFC* or less, as judged from the proportion of negative 
spleens (Table II) and from limiting dilution assays $(14,15)$, there was a striking excess of spleens with three or more foci. As the focus data were consistent with the analysis of macropieces of spleen (Fig. 1), it may be concluded that P-PFC* of specifically immunized mice had been selected for, or had acquired the property of, replication and migration before antigendriven terminal differentiation into PFC. This interpretation could account for the greater immunocompetence of P-PFC* in terms of their burst size and their rapid distribution within and, presumably, outside the spleen during secondary antibody responses. Both these attributes are characteristics of immunologic memory.

TABLE II

Multiple Hemolytic Foci in Spleens Seeded by One or a Few Bone Marrow Precursors of PlaqueForming Cells from Immunized Donor Mice*

\begin{tabular}{cccc}
\hline $\begin{array}{c}\text { No. of } \\
\text { foci per spleen }\end{array}$ & $\begin{array}{c}\text { Expected } \\
\text { percentages } \ddagger\end{array}$ & \multicolumn{2}{c}{ Observed percentages among recipients of } \\
\cline { 3 - 4 } & 37 & $24.5(53) \S$ & $34.0(47) \S$ \\
\hline 0 & 37 & 54.6 & 12.8 \\
1 & 18 & 11.4 & 8.5 \\
2 & 6 & 7.5 & 19.2 \\
3 & 2 & 1.9 & 25.5 \\
\hline
\end{tabular}

The table shows pooled data from two experiments in which irradiated mice were in jected with $5 \times 10^{7}$ thymocytes, $5 \times 10^{8} \mathrm{SRBC}$, and limiting numbers of bone marrow cells $\left(1-2 \times 10^{5}\right.$ immune cells, or $0.31-2.5 \times 10^{5}$ nonimmune cells). Hemolytic foci were enumerated in spleens of one-half of the recipients by the method of Playfair et al. (20), as modified by Kind and Campbell (21), and in those of the other half by the method of Kennedy et al. (19).

$\ddagger$ Calculated on the basis of the Poisson model.

$\S$ The total number of spleens assayed is in parentheses.

\section{DISCUSSION}

The results presented here and elsewhere $(13-16,18)$ strongly suggest that bone marrow-derived cells possess all the information necessary to dictate the specificity of the antibody response without help by other cell types. The demonstration that the number and immunocompetence of marrow P-PFC increase specifically upon immunization (reference 15 and Table I) and that the more efficient P-PFC* follow a different pattern of proliferation and differentiation than virgin precursor cells suggests that the immunologic memory of mice to SRBC rests primarily on marrow-derived cells. Although in these experiments the described manifestations of immunologic memory could be ascribed only to cells of marrow origin by design, such manifestations could not be improved by the cooperation of P-PFC* with educated instead of virgin thymocytes. The latter cells are also endowed with antigen specificity (3-8, $25,26)$, but their role may be better explained in terms of mitogenic or other 
stimulating factors acting over short ranges (27-29) rather than by informational molecules dictating specificity. It remains to be determined whether the memory cells were generated in, or migrated into, the marrow and whether thymic functions were required. Preliminary results indicate that memory cells of the kind described above are inducible in mice that have been thymectomized, irradiated, and reconstituted with marrow cells.

\section{SUMMARY}

Individual immunocompetent precursor cells of $(\mathrm{C} 57 \mathrm{BL} / 10 \times \mathrm{C} 3 \mathrm{H}) \mathrm{F}_{1}$ mouse marrow generate, on transplantation, three to five times more antibodyforming cells localized in recipient spleens during secondary than during primary immune responses. The increased burst size is immunologically specific since antigens of horse and chicken ery throcytes and of Salmonella typhimurium do not cause this effect in marrow cells responsive to sheep red blood cells. Both sensitized and nonsensitized precursors require the helper function of thymus-derived cells and antigen for the final steps of differentiation and maturation. The burst size of primed precursor cells is the same after cooperative interactions with virgin or educated helper cells of thymic origin. The greater potential of these marrow precursors may be attributable to selfreplication and migration before differentiation into antibody-forming descendants. In fact, the progeny cells of primed precursor units are distributed among a multiplicity of foci, whereas those of nonimmune precursors are clustered into one focus. The described properties of specifically primed marrow precursors are those underlying immunologic memory. It remains to be established whether memory cells are induced or selected by antigens and whether the thymus plays a role in this process.

\section{BIBLIOGRAPHY}

1. Claman, H. N., E. A. Chaperon, and R. F. Triplett. 1966. Immunocompetence of transferred thymus-marrow cell combinations. J. Immunol. 97:828.

2. Davies, A. J. S., E. Leuchars, V. Wallis, R. Marchant, and E. V. Elliott. 1967. The failure of thymus-derived cells to produce antibody. Transplantation. 5:222.

3. Mitchell, G. F., and J. F. A. P. Miller. 1968. Immunological activity of thymus and thoracic-duct lymphocytes. Proc. Nat. Acad. Sci. U.S.A. 59:296.

4. Shearer, G. M., and G. Cudkowicz. 1969. Distinct events in the immune response elicited by transferred marrow and thymus cells. I. Antigen requirements and proliferation of thymic antigen-reactive cells. J. Exp. Med. 130:1243.

5. Taylor, R. B. 1968. Immune paralysis of thymus cells by bovine serum albumin. Nature (London). 220:611.

6. Chiller, J. M., G. S. Habicht, and W. O. Weigle. 1970. Cellular sites of immunologic unresponsiveness. Proc. Nat. Acad. Sci. U.S.A. 65:551.

7. Chiller, J. M., G. S. Habicht, and W. O. Weigle. 1971. Kinetic differences in 
unresponsiveness of thymus and bone marrow cells. Science (Washington). 171:813.

8. Basten, A., J. F. A. P. Miller, N. L. Warner, and J. Pye, 1971. Specific inactivation of thymus-derived (T) and non-thymus-derived (B) lymphocytes by ${ }^{125}$-Ilabelled antigen. Nature (New Biol.) (London). 231:104.

9. Mozes, E., and G. M. Shearer. 1971. Contribution of bone marrow cells and lack of expression of thymocytes in genetic controls of immune responses for two immunopotent regions within poly-(Phe, Glu)-poly-Pro--poly-Lys in inbred mouse strains. J. Exp. Med. 134:141.

10. Raff, M. C. 1970. Role of thymus-derived lymphocytes in the secondary humoral immune response in mice. Nature (London). 226:1257.

11. Mitchinson, N. A. 1971. The carrier effect in the secondary response to haptenprotein conjugates. II. Cellular cooperation. Eur. J. Immunol. 1:18.

12. Paul, W. E., D. H. Katz, E. A. Goidl, and B. Benacerraf. 1970. Carrier function in anti-hapten immune responses. II. Specific properties of carrier cells capable of enhancing anti-hapten antibody responses. J. Exp. Med. 132:283.

13. Kennedy, J. C., P. E. Treadwell, and E. S. Lennox. 1970. Antigen-specific synergism in the immune response of irradiated mice given marrow cells and peritoneal cavity cells or extracts. J. Exp. Med. 132:353.

14. Miller, H. C., and G. Cudkowicz. 1970. Antigen-specific cells in mouse bone marrow. I. Lasting effects of priming on immunocyte production by transferred marrow. J. Exp. Med. 132:1122.

15. Miller, H. C., and G. Cudkowicz. 1971. Antigen-specific cells in mouse bone marrow. II. Fluctuation of the number and potential of immunocyte precursors after immunization. J. Exp. Med. 133:973.

16. Miller, J. F. A. P., and J. Sprent. 1971. Cell-to-cell interaction in the immune response. VI. Contribution of thymus-derived cells and antibody-forming cell precursors to immunological memory. J. Exp. Med. 134:66.

17. Levin, H. A., H. Levine, and S. F. Schlossman. 1971. Antigen recognition and antibody specificity. Carrier specificity and genetic control of anti-dinitrophenyl-oligolysine antibody. J. Exp. Med.133:1199.

18. Miller, H. C., and G. Cudkowicz. 1971. Density gradient separation of marrow precursor cells restricted for antibody specificity. Science (Washington). 173:156.

19. Kennedy, J. C., J. E. Till, L. Siminovitch, and E. A. McCulloch. 1966. The proliferative capacity of antigen-sensitive precursors of hemolytic plaque-forming cells. J. Immunol. 96:973.

20. Playfair, J. H. L., B. W. Papermaster, and L. J. Cole. 1965. Focal antibody production by transferred spleen cells in irradiated mice. Science (Washington). 149:998.

21. Kind, P., and P. A. Campbell. 1968. Differentiation of antibody-forming cells. I. Ratio of precursor cells to antibody-forming cells in the mouse spleen. $J$. Immunol. 100:55.

22. Shearer, G. M., and G. Cudkowicz. 1969. Cellular differentiation of the immune system of mice. III. Separate antigen-sensitive units for different types of antisheep immunocytes by marrow-thymus cell mixtures. J. Exp. Med. 129:935.

23. Shearer, G. M., G. Cudkowicz, and R. L. Priore. 1969. Cellular differentiation of 
the immune system of mice. IV. Lack of class differentiation of thymic antigenreactive cells. J. Exp. Med. 130:467.

24. Vann, D. C., and P. A. Campbell. 1970. Plaque-forming cells of two different origins in single hemolytic foci. J. Immunol. 105:1584.

25. Hartman, K.-U. 1970. Induction of a hemolysin response in vitro. Interaction of cells of bone marrow origin and thymic origin. J. Exp. Med. 132:1267.

26. Gershon, R. K., and K. Kondo. 1971. Antigenic competition between heterologous erythrocytes. I. Thymic dependency. J. Immunol. 106:1524.

27. Katz, D. H., W. E. Paul, E. A. Goidl, and B. Benacerraf. 1971. Carrier function in anti-hapten antibody responses. III. Stimulation of antibody synthesis and facilitation of hapten-specific secondary antibody responses by graft-versushost reactions. J. Exp. Med. 133:169.

28. Haskill, J. S., J. Marbrook, and B. E. Elliott. 1971. Thymus-independent step in the immune response to sheep erythrocytes. Nature (New Biol.) (London). 233:237.

29. Dutton, R. W., R. Falkoff, J. A. Hirst, M. Hoffman, J. W. Kappler, J. R. Kettman,J. F. Lesley, and D. Vann. 1971. Is there evidence for a non-antigen specific diffusable chemical mediator from the thymus-derived cell in the initiation of the immune response? Progr. Immunol. 1:355. 